\title{
Entrevista con Diego Rísquez: Descifrando el film Bolívar sinfonía tropikal (1980)
}

\author{
Rafael Arreaza Scrocchi*
}

Lugar y fecha de la entrevista: entre noviembre y diciembre del año 2016 por medio de varias conversaciones que tuve con Diego Rísquez quien estaba en su casa en Caracas, Venezuela.

Rafael Arreaza Scrocchi: Diego, entender a fondo tu film Bolívar sinfonía tropikal (1980) no es tarea fácil para quien no posee un conocimiento avanzado sobre la historia nacional e iconográfica de la época de la emancipación venezolana. ¿Qué opinas al respecto?

Diego Rísquez: Mi película sobre Bolívar está basada en la historia nacional enseñada en las aulas [Diego se refiere al pensum de estudio venezolano conocido como Cátedra Bolivariana o los cursos obligatorios de historia venezolana], a través de la cual se fusionan la historia y la iconografía para rememorar el pasado a través de la vida y obra del Libertador. Mi propuesta cinematográfica sobre la imagen de Bolívar mete en escena el pasado registrado en los lienzos, en las artes plásticas, y lo re-imagina de una manera distinta trasladando la iconografía a la gran pantalla. En Bolívar sinfonía tropikal, yo utilicé la cámara como si fuese un pincel para pintar a través de las escenas los momentos más importantes de la vida y obra de Bolívar. El film tiene dos vertientes: una para quienes pueden asimilar lo que ocurre desde el punto de vista histórico, literario o artístico, lo que es percibido a través de la conexión que existe entre la iconografía y la memoria nacional; la otra percepción, puede ser simplemente asimilada como un film experimental en que ocurren una serie de eventos que simbolizan una ráfaga de eventos en donde Simón Bolívar es el mensaje del film.

R.A.S.: Diego, la película tiene además una fusión muy particular entre literatura, historia y artes plásticas. Por ejemplo, se observa en el principio del film como tus imágenes rememoran situaciones narradas o pintadas en obras como: Esta Tierra de Gracia: imagen de Venezuela en el siglo XVI de Isaac J. Pardo, en la cual el inicio de tu película tiene mucho que ver con la llegada

\footnotetext{
* Vrije Universiteit Brussel - VUB, Faculty of Arts and Philosophy, Department of Language and Literature, Centre for Literary and Intermedial Crossings. 1050 Ixelles, Belgium. E-mail: Rafael.Arreaza-Scrocchi@vub.be
} 
de los españoles a las costas venezolanas relatada en esta obra; además, reimaginas imágenes pintadas por artistas como: Tito Rojas, Arturo Michelena, Martín Tovar y Tovar, y a Juan Lovera, por nombrar algunos. ¿Puedes explicar cómo reinterpretaste estos hechos históricos, literarios e iconográficos en el film?

D.R.: La película tiene muchísimas referencias nacionales que cronológicamente van expresando los acontecimientos no solamente más conocidos en la vida de Bolívar, sino que también invitan al espectador a recordar el pasado cultural, ése pasado en el que Venezuela vivió los inicios de la independencia representados al comienzo de la película con el conquistador español que llega a la playa destruyendo los frutos tropicales simbolizando el conflicto cultural que ocurrió durante la emancipación, durante la transculturización. La conexión entre la literatura, la historia y las artes plásticas siempre ha sido un tema que me apasiona y que utilizo en mi cinematografía. En Bolívar sinfonía tropikal se observan imágenes muy peculiares como la galería de personajes que acompañan a Bolívar en el inicio del film, o también, mi representación del cuadro de Arturo Michelena Miranda en la Carraca [Diego es Francisco de Miranda en el film], en donde el general Miranda está rodeado por los próceres de la patria que visten y emulan las poses en las que fueron retratados en el pasado. La particularidad de esta película fue mi propuesta para hacer algo distinto, una cinematografía totalmente opuesta a lo que se realizaba en el cine de los 70, 80, el cual carecía completamente de una temática nacional, tradicional, autóctona . Bolívar sinfonía tropikal tiene un sin fin de referencias históricas que son parte de la memoria nacional prácticamente indescifrables si no se conoce muy bien lo que le ocurrió a Bolívar durante los momentos más importantes de su vida.

R.A.S.: Diego, es el sonido de las olas del mar Caribe lo que inicia y lo que finaliza el film, también, la melancólica música expresada a través de un piano acompañado por una sinfonía orquestada que, meticulosamente, y en ocasiones in crescendo, acompaña las escenas de principio a fin invitando al espectador a formar parte de una película que fusiona los paisajes venezolanos visitados por Bolívar en conjunto con una sinfonía que ayuda a interpretar los altibajos un film silente. ¿Cuál es tu opinión al respecto?

D.R.: La música es sin duda alguna el hilo conector entre las escenas, los paisajes y los eventos en los cuales Bolívar aparece en distintas zonas geográficas en las que él estuvo. Por ejemplo, yo reflejo el matrimonio de Bolívar con María Teresa del Toro tomando en cuenta una pintura de Tito Rojas que reposa en la casa natal del Libertador; también, la muerte de María Teresa y 
Bolívar observándola en la cama, son escenas que nacieron del contraste entre lo biográfico y la iconografía que se encargó de registrar estos eventos que se trasladaron a la memoria colectiva y que quedaron plasmados en la historia nacional como parte de la cultura de nuestro país. Fíjate, en muchas escenas se observan los eventos más importantes de la vida personal y política de Bolívar, por ejemplo, su relación con la negra Matea en su infancia; las clases que recibió a través de Andrés Bello y Simón Rodríguez; los viajes a Europa; el retorno a Venezuela para luchar por la independencia; la aprehensión de Miranda en manos del mismo Bolívar, y muchos eventos que surgen y que se mezclan con la cultura tradicional venezolana que forma parte de mi cinematografía. El folklore nacional, la música, los colores patrios, la geografía en particular y una diversidad de cosas que forman parte del pasado venezolano, son parte del trasfondo del film en el cual la música acompaña las escenas en distintos paisajes del trópico venezolano.

R.A.S.: Muchas de las escenas ocurren en paisajes venezolanos realmente peculiares y quizás indescifrables para el espectador común, por ejemplo, escenificas a Bolívar en los médanos de Coro, una zona árida; también, recreas el cruce de los Andes en la laguna de Mucubají en el páramo, una zona nevada; en las playas de la Guaira, Bolívar alucina su muerte simbolizando sus últimos días en Santa Marta en la hacienda San Pedro Alejandrino; en la tupida selva de la Sabana acompañado por José Antonio Páez y los llaneros por nombrar algunos de estos lugares. Todos estos eventos y localidades están relacionados directamente con la emancipación venezolana y tú los replanteaste a través de la cámara dándole vida a la iconografía nacional. ¿Qué puedes compartir al respecto?

D.R.: La belleza natural que se percibe en los lienzos que ilustraron la época de la independencia muestran los paisajes de Venezuela de una manera quizás única. Lo que yo hice en el film fue tratar de llevar esas imágenes a la gran pantalla para no solamente sustentar visualmente los hechos que ocurren en el transcurso del film, sino también para complementar la trama con el trópico, con la selva, con los elementos más importantes de la emancipación.

R.A.S.: Reflejas en la pantalla de una manera intacta muchos de los cuadros que plantearon visualmente en el pasado muchos de los sucesos en los que Bolívar vivió. Por ejemplo, una de las escenas emula impecablemente el cuadro de Tito Salas titulado: Bolívar en el Chimborazo en donde Bolívar aparece divagando acompañado por un anciano que representa el tiempo. ¿Cómo ideaste esta escena? 
D.R.: Bolívar en el Chimborazo se me ocurrió filmarla en una fábrica de cal en donde todo era blanco en el fondo de la escena. Al mismo tiempo que Bolívar reflexiona en su soledad, el anciano que representa el tiempo, aparece de la nada entre una nube blanca que se dispersa rápidamente. Para esta escena utilicé un extinguidor que simula la niebla que cubre a Bolívar durante su delirio en el Chimborazo.

R.A.S.: Otro aspecto muy interesante es como el film presenta a través del simbolismo muchas de las situaciones que le ocurrieron a Bolívar en las batallas que a su vez fueron narradas en la obra Venezuela Heroica de Eduardo Blanco. Por nombrar alguno de los eventos, fusionas la muerte del negro primero, la presencia del general José Antonio Páez con su lanza y la famosa frase "vuelvan carajo", el caos de la guerra de independencia y la victoria de la misma manera como lo pintó Martín Tovar y Tovar en los lienzos que cubren el salón elíptico en Caracas rememorando la batalla de Carabobo que selló la independencia de Venezuela en 1821. ¿Recreaste todo esto en conjunto simbolizando el caos de la emancipación?

D.R.: La presencia de la guerra es imprescindible en la historia de Bolívar, en la historia patria venezolana en general. La escena de la batalla invita al espectador a formar parte de la confrontación desde el campo, como si se estuviese allí. Por medio de la cámara propongo observar directamente el desenlace del enfrentamiento entre Bolívar, sus generales y los españoles. Se observan detalles como la muerte de Pedro Camejo, conocido como el negro primero, simulando las últimas palabras que le dijo a Páez: "Mi general, vengo a decirle adiós porque estoy muerto", todos estos detalles están allí, lo que sucede es que pueden pasar por desapercibidos si no se conocen las frases o los eventos que acontecieron en la vida de Bolívar, en la historia de la emancipación venezolana.

R.A.S.: Ya que mencionas la guerra, hay dos escenas en particular que emulan en cámara lenta dos eventos muy importantes en la vida de Bolívar: uno es el fusilamiento del general Piar; el otro, el instante en el que Manuela Sáenz rescata a Bolívar del atentado septembrino. Estas situaciones tienen mucho que ver con la traición en manos de Piar y luego de Santander.

D.R.: La escena del fusilamiento de Piar muestra a Bolívar cubriéndole los ojos a Piar con una cinta que tiene los colores de la bandera venezolana la cual el mismo Piar se quita demostrando la desobediencia, la diferencia con Bolívar. La cámara hace la función del fusil y se observa el ajusticiamiento en cámara lenta. Lo mismo ocurre con la escena en que Manuela Sáenz rescata una marioneta que es un Bolívar en su caballo blanco tallado a madera que 
cuelga como si estuviese ahorcado simulando el intento de asesinato que sufrió Bolívar. Manuela, disparando un fusil hacia la cámara simboliza la defensa del Libertador. Hay que tomar en cuenta que Manuela Sáenz viste el uniforme de Bolívar y esto se debe a que el mismo Bolívar la llamó la Libertadora del Libertador.

R.A.S.: Simón Bolívar es además interpretado en dos formas. Se observan en varias escenas como aparecen dos Libertadores. ¿Se trata de un alter ego?

D.R.: Un Bolívar representa el Libertador patrio, el héroe que nos enseñaron en el colegio. El Bolívar de los libros de historia. El otro, es el Bolívar glorificado, el culto a su imagen, el que quedó registrado en la iconografía. Hay una parte en la que los dos Libertadores se enfrentan en un duelo frente al mar Caribe, también, puedes observa como uno de los Bolívar es cargado por esclavos simbolizando el Bolívar emperador, el que quería gobernar por siempre al final de sus días, hacia el año 1828 durante la fundación de Bolivia. En esa parte se observa como un Bolívar abandona a ése otro Libertador imperial. La dualidad de Bolívar reaparece también entre una pintura en donde se observa un tercer Libertador que es en teoría, el Bolívar que quedó plasmado en la historia, en las artes, en los lienzos.

R.A.S.: La decadencia y la alucinación del Libertador comienzan a notarse cuando reposa en la cama frente al mar, agarrado de la mano por el Doctor, Próspero Reverend. ¿Es esta una especie de muerte en cámara lenta, la cual además funciona como el hilo conductor de los eventos que son recordados por el mismo Libertador?

D.R.: Efectivamente. Es una manera quizás más melancólica la cual te invita a cuestionar que le sucedió a Bolívar en ese instante en particular. La presencia del mar es muy importante en esta escena porque Bolívar partió a Santa Marta, zona costera en Colombia, con la ilusión de emigrar para Europa, sin embargo, no lo logró porque falleció en la hacienda San Pedro Alejandrino. La escena con el Doctor Reverend expresa estos últimos días que vivió Bolívar.

R.A.S.: ¿Podría decirse que Bolívar entonces ya moribundo, alucina y recuerda todos esos instantes que tu película expresa de una manera muy peculiar invitando al espectador no solamente a formar parte de la trama a través de la música, el paisaje, el trópico, el surrealismo, el simbolismo, etc., sino que además, lo invita a la interpretación de un film silente que habla a través de las imágenes?

D.R.: Sí. La película transcurre a través de esa alucinación en la que Bolívar ve pasar los eventos más importantes de su vida paso a paso desde la 
cama frente al mar. El Dr. Reverend acompaña al Libertador en su viacrucis de la misma manera como lo narra la historia nacional.

R.A.S.: ¿Por qué el trozo de hielo al final de la película? ¿Qué es y qué representa ese bloque de hielo que se derrite en el tiempo en cámara rápida?

D.R.: El hielo es una escultura del busto de Bolívar. Si lo observas bien, es el rostro del Libertador, un busto tallado en hielo. Cuando hice la película en 1980, estas esculturas de hielo estaban muy de moda y se me ocurrió utilizar una para la película. Recuerdo que la encargué y la fui a buscar en mi carro, la metí en una cava y me fui manejando a la playa a tomar la escena. En teoría, el significado es ver como la imagen de Bolívar se va desvaneciendo en el tiempo, como desaparece al derretirse por completo. Al final, entonces queda el sonido de las olas que finaliza la película con un trozo de una carta que le escribió Simón Bolívar tres semanas antes de morir a Juan José Flores, presidente del ecuador en 1830.

R.A.S.: Muchísimas gracias por ayudarnos a esclarecer detalles tan peculiares, Diego. 